\title{
Reshaping the Value of Tourism Art from the Perspective of Neo-pragmatic Aesthetics*
}

\author{
Yan Zhang \\ Heihe University \\ Heihe, China
}

\author{
Hui Xie \\ Heihe University \\ Heihe, China
}

\begin{abstract}
As the inevitable result of the tourism economic mode, the tourism art is not only the important link in the tourism industry chain, but also the catalyst and power to realize the leaping development of the regional tourism. It is an important criterion to judge the current aesthetic experience and artistic value from Richard Schustermann's attention to the reality and the result of practice. It teaches people how to feel art in the process of experiencing life. Excellent travel art, is a tour of the history of the play, is a memorable cultural memory, is a passionate aesthetic encounter. Therefore, it is very important to probe into the remolding of the value of tourism art works from the perspective of neo-pragmatism Aesthetics.
\end{abstract}

Keywords—neo-pragmatism; tourism artwork; value reshaping

\section{INTRODUCTION}

With the development of global economic integration, the boundaries between disciplines, cultures, spirits and materials have become blurred. While people are enjoying the material life, they are participating in the construction of the whole human spiritual world. Tourism, as a symbol of the quality of life nowadays, extends to all levels of society in a silent way. The consumption influence and sense organ stimulation from the Middle Class are driving the consumers from all walks of life to the aesthetic convergence. Tourism, consumption at the same time, the birth of each region's culture, the rapid economic development, the optimal allocation of capital, and even the different regions of the excavation and re-culture of national culture. However, the invisible hand of the market is unable to point to the correct direction of cultural development in the Qing Dynasty while adjusting the pace of economic development, so the regional cultural construction under the tide of Tourism Economy, especially the reshaping of the value of tourism works of art, has become an unavoidable issue in the theoretical circle.

\section{AN OVERVIEW OF THE DEVELOPMENT OF CONTEMPORARY TOURISM ART}

As the inevitable result of the tourism economic mode, the tourism art is not only the important link in the tourism industry chain, but also the catalyst and power to realize the leaping development of the regional tourism industry. Due to the rapid development of the cultural industry, for the needs of

*Project Source: 2018 Heilongjiang Philosophy and Social Science Planning Project "study on the development path of tourism arts industrialization in Heilongiiang" (project number: 18YSE617). the cultural industry marketing, tourism products publicity, will inevitably put forward higher requirements for the design and production of regional tourism art. The concept of tourism artwork has already gone beyond the formal concept of traditional handicraft, and turned into a new category of individual with regional culture, economic factors, consumption habits, aesthetic identification. However, it is very regrettable that, corresponding to the development model of "culture + tourism" vigorously advocated by the state, quite a number of provinces and municipalities are still not sensitive to the concept of tourism artworks, and have not yet developed a conscious sense of innovation, merely equating tourism works of art with tourism souvenirs and tourism crafts. As a result, there is a dilemma in the development of tourism products in the north-south and east-west regions, such as borrowing and mixing of tourism products, lack of aesthetic taste in tourism art, emphasizing economic efficiency and neglecting cultural value. Taking the provinces of Yunnan and Guizhou in western China as an example, the unique artistic value of the tourism artworks in Yunnan and Guizhou cannot be matched by other provinces due to their unique human geography and long history of ethnic culture. The diversity of ethnic minority cultures, the exotic ethnic art forms and the centuries-old primitive mode of production are all fascinating for visitors who have experienced the arts and culture of Yunnan and Guizhou. However, careful study of the two provinces of Tourism Art, although the development of art in the forefront of the country, but there are still some aspects of the cultural tourism industry is worth exploring and thinking. First of all, from the perspective of the variety of tourism arts, there are far more types of arts in Yunnan and Guizhou than in other provinces, except for folk arts and crafts, clothing, luggage and bags with distinctive ethnic characteristics In music, dance, drama and other aspects of a comprehensive development, to Zhang Yimou's direction of Impression Lijiang and Danzhai County's most famous Miao Song and dance. However, due to the convenience of transportation, the consumption and exchange of tourism artworks have broken the original time and space limit. Many folk handicrafts from the native peoples of Yunnan and Guizhou provinces have been introduced into tourism attractions in other provinces. Ethnic songs and dances from Yunnan and Guizhou are played in business districts across the country. So it is easy to see why tourisms have flocked to Yunnan and Guizhou, only to return empty-handed. Secondly, from the aesthetic value of tourism artworks, the artistic elements and traditional production techniques of ethnic minorities in tourism artworks in Yunnan 
and Guizhou provinces deserve our appreciation and even collection from the perspective of intangible cultural heritage protection. However, the immortal value of art should not only be protected and inherited, but also be reformed and innovated to participate in social life. When we look at the works of art from Yunnan and Guizhou, we can hardly find more examples of their combination with reality. The aesthetic enjoyment they give people is often artistic. When people return to the fastpaced urban life, they will found that the purchase of tourism art aesthetic style and the mainstream aesthetic style still exists between the gaps, so cannot meet people's daily material and spiritual needs. Finally, from the point of view of the production of tourism artworks, the production of tourism artworks in Yunnan and Guizhou mostly presents a decentralized, individual, workshop-style production model, which to some extent solves the employment problem of the poor people in the remote mountainous areas. However, due to the "culture + tourism" business model of tourism artworks in the market economy environment, as a constantly expanding and improving cultural industry, it needs to absorb new elements into the thinking and creation of ancient art, and play an important role in the market management, life consumption, industrial revolution and supply-side reform. The current development needs of the cultural industry have run counter to the existing production and business models of tourism artworks in Yunnan and Guizhou. Of course, in the development of the cultural tourism industry, the western provinces of Yunnan and Guizhou have made many brilliant achievements, such as the protection of traditional skills and the application of elements with National Characteristics It is worthwhile for provinces like Heilongjiang and other provinces in the northeast to learn and use for reference in developing cultural and tourism industries. However, any learning and use for reference should be critical, and we should learn to reflect and use for reference from a historical perspective.

\section{TOURISM ART PROPERTIES IN THE PERSPECTIVE OF NEO-PRAGMATIC AESTHETICS}

Richard Shusterman ("Schusterman") joined Dewey and Rorty as the third-generation leader of American pragmatic aesthetics, and has considerable influence in Chinese philosophy and aesthetics. His philosophy is of a living philosophy, so Schusterman's pragmatism is mostly seen as a neo-pragmatism. His philosophical does not focus on the argumentation of propositions, but on the analysis of a way of life. With an empirical and qualitative dimension, it is likely to follow human culture and the rational opening of real life. Compared with other philosophers' attitudes and cold light, Schusterman's pragmatism is more practical, actionable and even emotional, which is can be seen in his arguments on many artistic aesthetic issues. In arguments on the value and significance of the art of living, he pointed out that the rich aesthetic resources contained in pop art are from the emotional experience in daily life, and are also the real path for the revival of current aesthetic experience based on many popular art (including rap art, country music, technical music, and urban aesthetics), with an idea of looking for the seeds of aesthetic renaissance in the ruins of the so-called art. Schusterman's neo-pragmatic aesthetics proposes the theory of dynamic aesthetic experience, which teaches us to understand the fine arts based on vivid experience rather than static objects" and the aesthetics shall be associated with the real life, and highlights the importance of future results and changes. It advocates making the art to be a part of life amid the society and history, fully considering its political, economic, cultural and other factors. From the above aesthetic perspective, it finds that the attention to reality and the emphasis on practical results are important for the neo-pragmatic aesthetics to judge the current aesthetic experience and artistic value, and is closely related to the value reshaping of current tourism art. As an important part of practical art, tourism art is a product of the rapid growth of commodity economy, and its commercial value property cannot be overlooked. However, as a work of art, the value property of tourism art cannot be limited to ordinary goods, and cultural value and aesthetic value are more important to the tourism art than the commodity value and practical value. Schustermann's neo-pragmatic aesthetics tell us that we shall see art in an inclusive and diverse way, and shall consider art philosophy as a holistic approach to artistic survival and self-control so as to achieve dynamic harmony in individuals and society. As a symbol of the emerging aesthetic experience, tourism art, it is worth that we discuss how its property and additional practicality and commerciality have always been going up in spirals in the dynamic development. For the national cultural industry, the cultural of tourism art is as important as its functionality, which is reflected in two aspects: commercial and art inheritance. Up to now, rare products are can be distilled and turned to tourism art in the regional tourism industry. The common traditional handicrafts, folk art, folk crafts often lose themselves' value while achieving function. The neo-pragmatic aesthetics advocates the popularization of aesthetic experience, and such development certainly does not mean to experience and feel life while completely losing itself. The wisdom of the neopragmatic aesthetics lies not in the experience, but in teaching people how to feel art while experiencing life, which is very important for value reshaping of tourism art. It reminds all personnel engaged in design, development and production of tourism art that it is necessary to stay conscious to integrate the works into experience of people's daily lives, but also raise awareness to the art value of the tourism art, of which find a real and useful way to establish tourism art properties.

\section{THE NECESSITY AND SPECIFIC WAYS OF RESHAPING THE VALUE OF TOURISM ARTWORK}

In the ever-changing urban, fast-paced work and life often cause people to be in a state of loneliness, emptiness and even imbalance in the psychological and emotional long-term, so they return to the way of tourism through economic conditions. Simple and comfortable, the unfamiliar environment brings people the relaxed and comfortable lifestyle that is indispensable to the present, which also creates new opportunities for the rapid development of the domestic tourism industry. The tourism art related to the tourism industry, with its innate innocence and humanistic care, has become a good medicine to soothe the souls of the lonely people on the road. Of course, it will also become a promise and sustenance for passengers to return to urban life. Therefore, 
it is an unavoidable question to reflect on the significance of tourism artwork and reshape the value of tourism artwork.

As a unique artistic form, tourism artwork firstly stimulates the visual beauty and aesthetic experience of the viewer. Through its external form, it becomes the logical and life way of a certain encounter with the tourism's mind. The more you study the structure of art, the more you will find the similarities between the art and life..." Becoming a reflection of the life activities of tourisms. When visitors appreciate the tourism artwork, they can appreciate the life meaning and emotional characteristics of the tourism artwork, giving people a warm and positive energy, and enriching the soul and nourishing the spirit. Secondly, the tourism artwork is designed according to the local customs, folk customs, geological features, historical legends, etc., and often records the daily life and historical context of the inhabitants of the world. Excellent tourism artwork can be a historical repertoire, an unforgettable cultural memory, and a passionate aesthetic. From the very beginning of its birth, tourism artwork has participated in the transformation of the market economy. It is born with multiculturalism and pluralistic values, and undergoes the process of intervention, competition, integration and reshaping. Through the reorganization of various production methods, the low-efficiency individual processing industry is gradually transformed into the handicraft cultural and creative industry, which has become a new direction to promote regional culture, regain the essence of art, establish a good life belief, and build a harmonious and happy home.

Based on the necessity of the above-mentioned tourism artwork to the public life, it is very important to reshape its value connotation from the perspective of the sustainability of the future development of the tourism industry. Specifically, we can carry out strategic thinking through the following ways. First, identify cultural positioning and conduct rational design and development. Tourism artwork should grasp the tourism target market and competition ecology in a comprehensive way. We will invest a lot of energy and material resources to design and disseminate the brand image of the regional culture, use the Internet technology to increase the influence propaganda, open the reputation and popularity, and thus aim at the target tourism. In the minds of consumers, the establishment of cultural brands, on the basis of the previous brand concept, the integration of historical and cultural elements and spiritual quality in the design of tourism artwork, combined with the psychological needs of tourisms to develop the corresponding artwork. Second, create artistic scenes to stimulate the appreciation and consumption of tourism artwork. According to the latest market research, the most interesting tourism projects are the contextualized and experiential projects, and the daily aesthetic experience is established in the process of experience. As mentioned above, Schuster's neopragmatic aesthetics advocates the concept of replacing traditional aesthetics with physical experience. Action and experience are the most acceptable aesthetic methods for the public. Therefore, by creating a deep cultural environment for tourism artwork, we will create an intuitive and vivid cultural memory and artistic association for tourisms, thus bringing the distance between tourism artwork and tourisms closer, so that they can participate in the aesthetic experience. Visitors are willing to appreciate and consume the artworks. Third, pay attention to the comprehensive packaging of tourism art and strive to create unique tourism art. The packaging of tourism art is far more than the packaging of artworks and accessories, but is the comprehensive creation of cultural connotation of tourism art, shopping experience, audiovisual sense, logistics services, etc., and makes a upgrading of travel art from the outside to the inside, from quantity to quality, to create a tourism's aesthetic experience with an artistic consumer experience. Mature tourism art must not be an isolated entity. It needs the support and promotion of relevant industries. Only by comprehensive creativity and assisting each other can make it become a unique travel art that tourisms are willing to consume.

\section{CONCLUSION}

Tourism artworks are never a specific form, but a dynamic art phenomenon that participates in the construction of contemporary economy and culture. Their pluralistic, comprehensive and practical features cover almost all the contents of People's Daily Life as Schustermann put it in life is pragmatism, "a primary purpose of art is to integrate art and life more closely by recognizing the universal importance of aesthetic experience beyond the realm of beauty." Therefore, under the vision of neo-pragmatism aesthetics, tourism art works should be guided by philosophy; aesthetics and artistic concept, continuously absorb the practical achievements of human art history, and create new aesthetic taste of human culture So as to meet the growing public aesthetic needs for the development of cultural industries to provide an important material support.

\section{REFERENCES}

[1] Yao Wenfang, [USA] Richard Schustermann, translated by Gao Yanping. A Dialogue Between Pragmatism, Bodily Aesthetics and Chinese Culture - An Interview with Professor Schustermann [J] . Foreign Aesthetics, 2017(27) . (in Chinese)

[2] [US] John Dewey. Art Is Experience [M] . BEIJING: Commercial Press, 2005 .

[3] [US] Richard Schustermann. Pragmatic Aesthetics [M]. BEIJING: Commercial Press, 2002.

[4] Liu Delin. Schustermann's Study of Pragmatic Aesthetics [D]. Shandong: Doctoral dissertation, Shandong University, 2005. (in Chinese)

[5] [US] Susan Langhe. Translated by Teng Shouyao and Zhu Jiangyuan. Art Problems [ m ] BEIJING: China Social Sciences Press, 1983.

[6] [US] Richard Schustermann, translated by Peng Feng. Life is Aesthetic [ M ] . BEIJING: Peking University Press, 2007. 